\title{
Retraction Note to: Effects of a Terrified-Sound Stress on Serum Proteomic Profiling in Mice
}

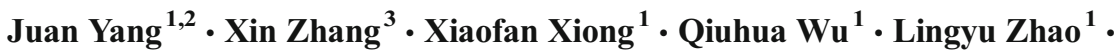 \\ Liying Liu ${ }^{2}$ - Yannan Qin ${ }^{1}$. Tusheng Song ${ }^{1}$. Chen Huang ${ }^{1,2}$
}

Published online: 26 August 2016

(C) Springer Science+Business Media New York 2016

Retraction Note to: J Mol Neurosci (2015) 57:211-218

DOI 10.1007/s12031-015-0607-5

This article is retracted as consented by the authors, Editor-inChief and publisher for the following reason: The human and mouse samples were mixed (by mistake) and the results shown for the mouse are actually human sequences.

The authors regret the mistake and apologize to the readers.

The online version of the original article can be found at http://dx.doi. org/10.1007/s12031-015-0607-5.

Chen Huang

hchen@mail.xjtu.edu.cn

1 Department of Cell Biology and Genetics, Basic Medical School, Xi'an Jiaotong University, 76 Western Yanta Road,

Xi'an, Shaanxi 710061, People's Republic of China

2 Key Laboratory of Environment and Disease-Related Gene, Ministry of Education, Xi'an Jiaotong University, 76 Western Yanta Road, Xi'an, Shaanxi 710061, People's Republic of China

3 Assisted Reproduction Center, Maternal \& Child Health Care Hospital, Xi'an, Shaanxi 710003, People's Republic of China 